\title{
Free Energy Bike
}

\author{
Jogendra Ghodke ${ }^{1}$, Siddharth Kadam², Mayur Kolhe ${ }^{3}$, Yogita More ${ }^{4}$, Kishor Mahajan ${ }^{5}$ \\ ${ }^{1,2,3,4}$ UG students, Department of Mechanical Engineering, Godavari College of Engineering, Jalgaon, India \\ ${ }^{5}$ Assistant professor, Department of Mechanical Engineering, Godavari College of Engineering, Jalgaon, India
}

Received on: 16 July, 2021

Revised on: 15 August, 2021

Published on: 17 August, 2021

\begin{abstract}
There are so many vehicles that came to influence in the existing world. Their operating systems are based on usual fossil fuel system. At the present sense the fossil fuel can exceed only for a certain period. Thus, an attempt is made to design and fabricate an ultimate system (free energy bicycle) which would produce cheaper \& effective result than the existing system. This will be very useful to the future needs of the world. An attempt is made in the fabrication of a free energy System for a two-wheeler (bicycle). This works on electric power distributed by the D.C electric motor receiving the current from a battery. Battery is charged by using dynamo. The motor and the various parts are such as sprocket, chain assembly and bicycle with easily available materials this project can be broken down into five separate categories: the lithium-ion battery, the DC$D C$ boost converter, the alternator, the motor, and the motor controller. Each of these will be built upon and improved further in future. The hope is that this design can become very efficient, cost-effective, and one day mass-produced, especially in developing countries where automotive transportation is an impossibility.
\end{abstract}

Keywords: Electric bike, Alternator, Batteries, Free energy

\section{I- INTRODUCTION}

All vehicles that are in the market cause pollution and the fuel cost is also increasing day by day. In order to compensate the fluctuating fuel cost and reducing the pollution a good remedy is needed. That is free energy transporting system. The device described in this project integrates an alternator and a bicycle, allowing the power generation of environment friendly. This contemplates both personal health and environmental issues.

When we see whole world facing problems regarding the fuel. We sucked more than 135 million of crude oil to drive our vehicles. The reservoir of oil has to end we need to change the fuel for the vehicles.

So we developed an electric bike which is self-charging using the kinetic energy and inertia of the wheel of bike.

The extra benefit to building the free energy bike is that it can also show the general public how much cheaper it would be to convert their regular bicycle into an electric bicycle rather than driving solely in their gas-powered vehicles. The greater importance of the environment in the world leads to an opportunity for students in our position. With the economy trying to get out of one of the worst depressions of the century, there are numerous opportunities for us to help out. This is our opportunity to contribute a greener and more efficient planet.

\section{II - LITERATURE REVIEW}

The electric bike as compare to other fuel as must cheaper in rate but it's have some limitation. The research on the new fuel technology is going on in various country. 


\section{International Journal of Innovations in Engineering and Science, www.ijies.net}

As we see the electric bike available in market is the best solution over the petrol vehicle but, it needs 8 to 9 hours charging. In recent years, squirrel cage induction machines are used as the electromechanical energy converter. The principle of self-excitation applied to the induction machines to generate electricity. According to Tze-Fun (1888), an induction machine called as selfexcited induction generator (SEIG), when a suitable capacitance is connected across the stator winding of an induction machine and self-excitation occur under favorable conditions. SEIG is good candidate for electric generation applications, because they do not need external power supply to produce the magnetic field. According to D. Seyoum et al. (2000) permanent magnet generator can also be used for energy applications but they suffer from uncontrollable magnetic field, which decline over a period due to weakening of the magnets, and generated voltage tends to fall steeply with load. The electro magnet not work properly.

Then the china is also the largest manufacture of electric bikes such that the problem is the bikes not achieve more than $20 \mathrm{~km} / \mathrm{hrs}$. Speed

This all have limitation so we need the solution on it to achieve

1. Environment friendly fuel.

2. Good transportation

3. Cheap rate fuel

4. Speed.

\section{III -METHODOLOGY}

Proposed work started with the studying the requirement of vehicle fuel because of day by day increase the cost of fuel and from existing fuel it harmful for our environment. The electric bike available in market needs up to 8 hours charging. So we start finding solution on it.

When we see the bike in running condition the wheel of bike have energy on it which is kinetic energy so we utilize that energy to charge the batteries of electric bike.

Main principle :It works on the principle that the kinetic energy of wheel when the vehicle run it utilized with the help of alternator which produced A.C current that will convert into DC. And charges the batteries of electric vehicle.

The project is described in four parts which is balance body, Transmission, power source, energy conversion.

Table 1 - Parts list

\begin{tabular}{|c|c|c|}
\hline Sr.NO. & Part Name & Description/Material \\
\hline 1 & Chassis & Aluminum \\
\hline 2 & BLDC motor & 24 volts \\
\hline 3 & Battery & 24 volts \\
\hline 4 & Alternator & 12 volts \\
\hline 5 & Controller & 8 ports \\
\hline 6 & $\begin{array}{c}\text { Bridge rectifier } \\
\text { and step-up mixer }\end{array}$ & $\begin{array}{c}\text { For conversion AC to } \\
\text { DC charge. }\end{array}$ \\
\hline 7 & Extended axles & 12 inch. \\
\hline
\end{tabular}

Above table consist main parts. There are so many parts like throttle, Circuit, Battery indicators, Control panel, Head lamp, Breaking system, battery box, etc.

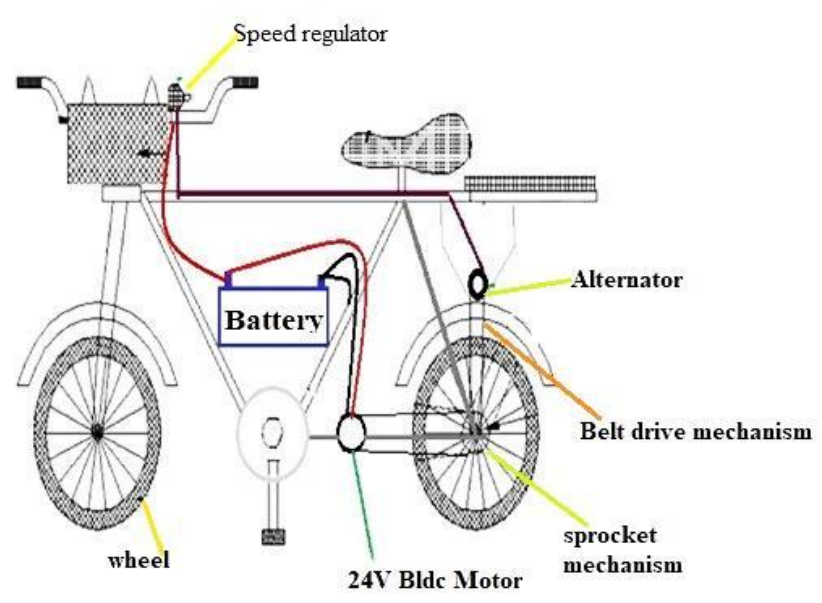

Fig.1 - Basic View of Free Energy Bike

\section{1) Balance Body:-}

The chassis of bike is fully fabricated because of the arrangements of parts on it. On back side the body should be designed like it can between gap increased for wheel and pulley both. We choose the material of chassis is aluminum because of light in weight.

2) Transmission system:-

In the transmission system covers major parts of project for transmission system we use both sprocket and belt drive mechanism. -BLDC Motor: the motor gives power to our bike the motor is coupled with back wheel with the help of sprocket and chain mechanism. The motor gives power from batteries.

Table 2 - Specifications

\begin{tabular}{|l|c|c|}
\hline 1 & Output power & $250 \mathrm{~W}$ \\
\hline 2 & Supply voltage & 24 Volts \\
\hline 3 & Rated Speed & 2350 RPM \\
\hline 4 & No Load speed & 3000 RPM \\
\hline
\end{tabular}

\section{3) Power source: -}




\section{International Journal of Innovations in Engineering and Science, www.ijies.net}

The power source of our system is 24 volt batteries connected with alternator and BLDC motor. We use 12 volts of two batteries and connect it in series so final output we get 24 volts for our system.

Voltage of batteries - 24 volts

Ampere - 14 amp.

4) Energy conversion: -

We modify the back wheel of bike and attach it a pulley for belt drive for alternator so we connect alternator and when the wheel start moving it get generate Ac Charge with help of $12 \mathrm{v}$ alternator. So we make bridge rectifier to convert AC charge into DC charge and step up mixer for convert 12 volts into 24 volt to charge our batteries.

\section{IV- DESIGN}

There are many requirements that need to be met to produce a product that is both feasible and optimal. There are also some constraints, both geometric and engineering that also need to be satisfied

For the design we consider all parameter i.e. Size, shape, material, body, etc. according to calculation:

\section{$\mathrm{P}=2 \pi \mathrm{NT} / 60$}

P-Power in $\mathrm{W}, \mathrm{N}-$ Speed in rpm, T-Torque in N-m

$\mathrm{T}=r \pi \mathrm{D} 3 / 16$

D- Diameter of the wheel in $\mathrm{m}$,

$r$-Shear stress $=20 \mathrm{~N} / \mathrm{mm} 2$.

$\mathrm{D}=548 \mathrm{~mm}$

$\mathrm{T}=3.14 * 20 *(548) 3 / 16$

$\mathrm{T}=645.92 * 10-3 \mathrm{~N}-\mathrm{m}$.

Power $=2 * 3.14 * 200 * 645.92 * 10-3 / 60$

$\mathrm{P}=13.52 \mathrm{~W}$

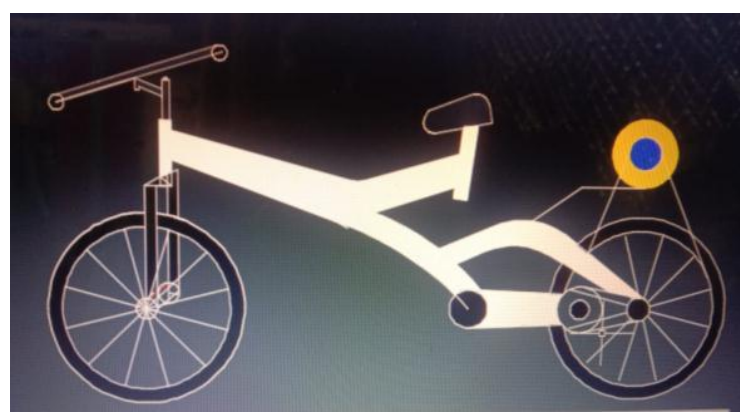

Fig. 2 - 3D view of Bike

\section{V- WORKING}

The major challenge is facing in the project is to work the project properly and get the final out which is charge the batteries. When we start ignition on the front panel which is key holder start the accelerator to motor the motor connected with back wheel start working the bike move forward. When the back wheel start rotating the pulley attached with wheel also start rotates and the alternator and pulley connect with help of belt that for alternator also start rotating. The alternator is device which convert mechanical energy into electrical energy, so alternator start generate AC charge for our system to charge batteries we need DC charge so with help of rectifier and step up mixer we get the DC output and charge our system batteries.

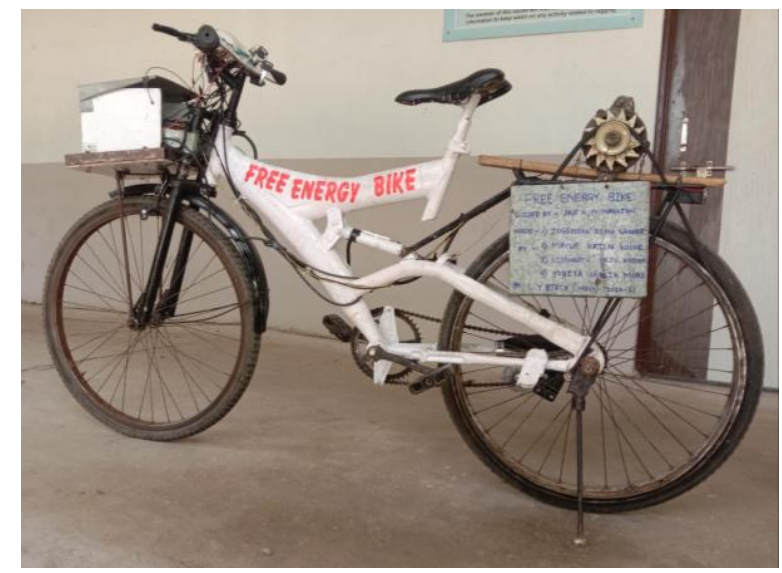

Fig.3-Actual view of Free Energy Bike

\section{VI - RESULT}

The free energy concept is violet the law of conversion of mass and energy which is "energy neither be created nor be destroyed" as we know the energy crises in whole world, we want to generate energy and utilization of energy.

Time required for charging the batteries:-

Volt - 12 volt of two batteries connected in series so we get final 24 volts.

Ampere $-7 \mathrm{Ah}$ of one and final we get $14 \mathrm{Ah}$.

Power -13.52

Dividing power value for in kilowatt.

$\mathrm{U}-$ Capacity in volts.

I - current. 


\section{International Journal of Innovations in Engineering and Science, www.ijies.net}

Load on batteries $-\mathrm{P}=\mathrm{U}$ x I

$$
\begin{aligned}
& =24 \times 14 \\
& =336 \mathrm{~W} . \\
& =0.336 \mathrm{KW} .
\end{aligned}
$$

Charging time - power of battery / power

$=0.084 / 0.336$

$=0.25$. Mines the time required to charge the battery is 2 hours/5minutes.

Also you can minimize the time of the charging for that you want to off ignition switch and on charging buttons and with the help of the paddling you charge the batteries.

\section{FUTURE SCOPE}

The free energy bike is best option for us as compared to petrol vehicles. Using the free energy we charge the batteries of our bike but in some condition we need to some more time to charge the batteries for that in future we should attached the solar panel as a roof on our bike so we generate more electricity from convert sun energy into electric energy and charge the batteries quickly and increase the ability of our bike.

And in future we used it for long distance and also in transportation.

\section{VIII- CONCLUSION}

This project is made with preplanning, that is provides flexibility in operation and noise less operation by the medium of free energy bicycle. This free energy bicycle is very useful to the transportation for children and old people. Because no need to pedal the bicycle. By using this vehicle, no fuel is needed to run the vehicle and it is pollution free vehicle. It is designed with the hope that is very much economical vehicle. Also it is very cheaper as compare to petrol vehicles. Also it efficient and helpful to day by day use and less the pollution. Now the reservoir of petrol and diesel, natural gas has at to end stage so we want to accept the new technology and idea.

Using the free energy bike the pollution get controlled by us and our economy get stronger and the new experience feel. Due to our busy life we forget our body health we need to exercise for healthy life for that free energy bike is greatest option for us.

\section{REFERENCES}

[1] Siddharth K. Patil., "Regenerative Braking System in Automobiles", International Journal of Research in Mechanical Engineering \&Technology vol.2, pp.4546, 2012.

[2] Chibulka.J., "Kinetic Energy Recovery System by means of Flywheel Energy Storage", Advanced Engineering Vol. 3,No. 1, pp. 27-38,1998.

[3] S.J.Clegg, "A Review of Regenerative Braking System”, Institute of Transport Studies, University of Leeds, Working paper of 471, 1996.

[4] Saharat Chanthanumataporn, SarawutL erspalungsanti and Monsak Pimsarn, "Design of Regenerative Braking System for an electric vehicle modified from used car", Second TSME International Conference on Mechanical Engineering, 19-21 Oct, 2011.

[5] Dr. Iqbal Husain, "Electric and hybrid Vehicles: Design Fundamentals", CRC press, Taylor and Francis Group, USA, 2012.

[6] Gao, Y., Chen, L., Ehsani, M., "Investigation of the Effectiveness of Regenerative Braking for EV and HEV",SAE Paper 1999-01-2910,1999.

[7] John M. Miller, "Propulsion Systems for Hybrid Vehicles", Institute of Electrical Engineers, UK, 2004.

[8] Chen, J-X, Jiang, J-Z. Wang, X-J., "Research of Energy Regeneration Technology in Electric Vehicle", Shanghai University Press, Vol. 7, No 2, pp.25-36, 2008.

[9] Papalambros, P.Y., and D.J. Wilde, "Principles of Optimal Design", 2nd Ed. Cambridge University Press, New Your, NY, 2010. 